\title{
The Effect Of Benevolent Leadership On Organizational Citizenship Behavior (OCB) : Mediating Role Of Ethics Climate
}

\author{
Muhidin ${ }^{1}$, Usman Rianse ${ }^{2}$, Nurwati ${ }^{3}$, Rahmat Madjid ${ }^{4}$ \\ ${ }^{1}$ Doctoral Program of Management Science, Halu Oleo University Kendari Southeast Sulawesi, Indonesia \\ ${ }^{2,3,4}$ Halu Oleo University, Southeast Sulawesi, Indonesia
}

\begin{abstract}
-
This study was conducted to examine the effect of benevolent leadership (ethics sensitivity, spirituality, positive engagement, and community responses) to organizational citizenship behavior (OCB), either directly, or through mediation Ethics Climate. The study was based on a survey of 200 respondents. Respondents were used in this study came from Department of Education and Culture in Kendari. The research data used cross sections data so it is possible perception of respondents is different because of the time and place, so it is advisable to research will be able to use time series. Statistical Package for the Social Sciences used to test the hypothesis. The results showed that ethics sensitivity has significant positive effect on OCB. Ethics Climate mediates the relationship between ethics sensitivity and OCB. Spirituality has no effect on OCB. Ethics Climate does not mediate the relationship between spirituality and OCB. Positive engagement does not affect the OCB. Ethics Climate does not mediate the relationship between positive Positive engagement and OCB. Community response had no effect on OCB. But Ethics Climate response mediates the relationship between community and OCB. Ethics Climate has significant and positive effect on $O C B$.
\end{abstract}

Keywords: Benevolent Leadership (sensitivity of ethics, spirituality, positive engagement, community response), Ethics Climate, Organizational Citizenship Behavior

Date of Submission: 12 November $2016 \longrightarrow$ Date of Accepted: 22 November 2016

\section{INTRODUCTION}

The government organization formed to provide the public with the best. Efforts of service is determined by the ability of personnel resources who work in them are leadership skills, professionalism, insight, experience, and work behavior (Harsono, 2010). In organizations, the problem is always interesting and never-ending discussion is the ability of leadership (Bass and Riggio, 2006). Leadership skills of a leader is a key factor to the success of an organization (Luthans, 2011). Strategic and leadership skills are very important for the achievement of the mission, vision and goals of an organization (Robbins, 2003). The leader is the main actor black and white defines the organization and members of his subordinate (Nawawi, 2006). The leader's role is very large in motivating members of the organization as well as enlarges the energy in the act to achieve group goals (Armstrong, 2010). A wise leader is deemed able to oversee organizational sustainability and the creation of better welfare (Karakas and Sarigollu, 2012). A leader is not to be served but how to serve, guide, and create a sense of well-being and justice (Rianse, 2012).

In concept, benevolent leadership is the integration of the four fields of study research organizations: ethics, spirituality, vitality, and community response. Aspects of morality focus on morals and values and ethics leaders (Robbins, 2003), the spiritual aspects focus on mysticism and religious values leader (Fry, 2005), the aspect of vitality focus on how leaders inspire and create positive change in the organization (Scheimann 2010), aspects of community responses focus on service and contributions leader on social and community issues (Caracas and Sarigollu, 2012). Benevolent leadership philosophy based on the belief that human nature has the potential for good that tend to sharing, loving, well behaved and charity. The purpose of integrating morality, spirituality, vitality, and community responses into one concept in order to create the common good of the organization, overcoming challenges and crisis-paced competitive world, as well as adapt and react quickly in the face of change (Gosh, 2015).

Scientifically, according to Karakas and Sarigollu (2012) and Ghosh (2015) elements benevolent leadership consists of ethics sensitivity, spirituality, positive engagement, and community responses. Research Karakas and Sarigollu (2012) at 175 business organizations and nonprofit managers in Canada, concluded that the variable ethics sensitivity, spirituality, positive engagement, and community response has significant and positive effect on organizational performance, effectiveness of commitment, and organizational citizenship behavior (OCB). Similarly, research Ghosh (2015) conducted on 200 leaders in eight nonprofit organizations in 
India, concluded that the variable ethics sensitivity, spirituality, positive engagement, and community response has significant positive effect to OCB, either directly, or through the mediation of Ethics Climate. In this study the ethics sensitivity, spirituality, positive engagement, and community response is treated as a variable follow justification of previous researchers.

The role of a leader in an organization can affect climate or culture of ethics organization (Bass, 1985; Schwepker, Ferrell and Ingram, 1997). The success of leadership will drive the climate and ethical organization towards better (Schein, 1983). Climate is an indicator of whether the beliefs and expectations will be fulfilled (Bowditch and Buono, 1990). Ethics refers to the basic rules and moral values that govern the behavior of a person or group to what is right or wrong (Daft, 2010; Luthans, 2011; Robbins and Coulter, 2012). Ethics Climate in the organization is a shared perception of what true ethical behavior is and how ethical issues should be handled (Victor \& Cullen, 1987; Luthans 2011; Schwepker, 2001). Several empirical studies prove that Ethics Climate has significant influence the development of the organization, including the development of OCB, either directly or through mediation (Huang, 2012; Zehir et. Al., 2014; Shin et.al, 2015).

The issue of leadership and the behavior of employees in the above becomes urgent to be studied, particularly benevolent leadership that has to do with the behavior of OCB. Leadership is key in the management and strategic play an important role in the survival of an organization (Luthans, 2011; Bass, 1985). The leader is the originator of interest, plan, organize, mobilize and control all available resources so that organizational goals can be achieved effectively and efficiently (Certo and Certo, 2012), therefore the leader of an organization is required to always be able to create satisfactory conditions of employees in work that earned by the employees who are not only able to work but are also willing to work toward the achievement of organizational goals (Robbins-Judge, 2013). The success or failure of most organizations is determined by the quality of leadership that is inherent in the people who occupy a position of leadership in the organization (Siagian, 1995). Leadership qualities can improve the effectiveness and performance of organizations (Organ et. $\mathrm{Al}, 2006)$.

Theoretical arguments and empirical above becomes the starting point of the development of research forms with the aim to examine the relationship model benevolent leadership; ethics sensitivity, spirituality, positive engagement, and community response to OCB, either directly, or through the mediation of the Ethics Climate and confidence in Department of Education and Culture in Kendari.

\section{Benevolent leadership}

\section{LITERATURE REVIEW}

According to the dictionary definition benevolent leadership has similarities with wise leadership (Echols and Shadily, 2010). Benevolent leadership pleased with authenticity, dignity and the common good (Karakas \& Sarigollu, 2012). Scholars in China align the concept of benevolent with the teachings of Confucius, which the leaders must be able to demonstrate the behavior of caring for the welfare of subordinates (Niu et al., 2009; Wang \& Cheng, 2010). Benevolent leadership is an expression of benevolence, the will and good intentions, and the actions taken by the leader for the greater good (Ghosh, 2015). Benevolent leadership not to be served but rather how to serve, guide, and create a sense of well-being and justice (Rianse, 2012).

Benevolent leadership philosophy based on a belief in which a natural human instinct contain the potential for good that tends to love one another, do good, and charity (Ghosh, 2015). Furthermore Karakas and Sarigollu (2012) stated that the benevolent leadership is the idea of a model of leadership for the common good premises integrating four broad areas of research organizations, namely morality, spirituality, vitality, and community response. Each field has its own focus, scope and benefits of its application in the organization. Effective Benevolent leadership to overcome the crisis of leadership, overcoming the turbulence organizations and businesses, facing the fast-paced changes (Ghosh, 2015). The scope of the benevolent leadership as well as the benefits of its application in the organization is as follows:

a. The sensitivity of the ethical use of the paradigm of morality that comes from business ethics, values and ethical leadership, ethical decision-making as well as literature (focus on the ethics and values of the leader);

b. Spirituality using spiritual paradigm that comes from spirituality in the workplace and spiritual leadership literature (focus on mysticism and the spiritual leader of action);

c. Positive engagement is constituted by positive science and strength-based approach (focus on how leaders create positive change in the organization and the world);

d. Community response based on corporate social responsibility and corporate citizenship literature (focus on service and contributions leader on social and community issues). 
The Effect Of Benevolent Leadership On Organizational Citizenship Behavior (OCB) : Mediating ..

\section{Ethics Climate}

Ethics refers to the basic rules and moral values that govern the behavior of a person or group to what is right or wrong (Daft, 2010). Ethics involves moral issues and choices in the face of behavior are right and wrong (Luthans, 2011). Ethics are the principles, values, and beliefs that determine the behavior and decisions of right and wrong (Robbins and Coulter, 2012). While the climate is an indicator of whether the beliefs and expectations will be fulfilled (Bowditch and Buono, 1990).

Ethics Climate in the organization is a shared perception of what true ethical behavior is and how ethical issues should be handled (Victor \& Cullen, 1987). Factors forming the ethical behavior of the organization come from the code of ethics, role models, regulatory practices, as well as the system of reward and punishment (Luthans, 2011). Furthermore, Victor and Cullen (2008) states there are five dimensions to measure the organizational Ethics Climate that is; caring, law and legislation, rules, instrumental, independence. a. Concern; ethical standards based on the virtues of caring for others;

b. Law and legislation; decision should be based on ethical standards, laws and professional codes of conduct c. rules; a standard ethical principles such as the code of ethics

d. Instrumental; a decision made for the interests of the organization or for personal gain

e. self-reliance; individual action on their own moral convictions based on principles that are considered good.

\section{Organizational Citizenship Behavior (OCB)}

Organizational citizenship behavior (OCB) is the individual contribution that exceeds the demands of the role in the workplace (Podsakoff et al, 2000). Individuals not only complete the main task (in-role), but also willing and able to complete tasks outside its core functions (extra-role) (Pearce, 1991). Extra-role effort as a form of employee loyalty to achievement the maximum organization (Katz, 1964). Also describe the added value of employees as a form of prosocial behaviors that are positive, constructive and meaningful help (Brief and Motowildo, 1992). Including behaviors like helping others, volunteering for extra duties, adherence to the rules and procedures in the workplace (Organ 1988). Furthermore, Organ et. al, (2006) defines OCB as a free individual behavior, not directly or explicitly associated with the reward system and can increase the effective functioning of the organization. OCB does not require that the requirements of the role or job description, which clearly required under the contract with the organization, but as a personal choice. The point is voluntary behavior rather than coercion as a form of satisfaction based on performance (Borman and Motowildo, 1993; Organ et. al., 2006).

\section{Benevolent Leadership and Organization Citizenship Behavior}

First study that tested the benevolent leadership and organization citizenship behavior is Karakas and Sarigollu (2012) entitled "Benevolent Leadership: conceptualization And Construct Development". In this study the concept of benevolent leadership built using arguments DeVellis (1991), Walumbwa et al. (2008), Schriesheim et al. (1993), and Suddaby (2010). Elements forming the benevolent leadership exploratory then factor analysis and confirmatory factor analysis on 175 business organizations and nonprofit managers in Canada. From the analysis found elements forming the benevolent leadership, namely, ethical sensitivity, spiritual depth, positive engagement, and community responsiveness. Further elements forming the Benevolent Leadership used variable to be associated with an organization's performance, effectiveness commitments, and OCB by using structural equation modeling. The results showed that the benevolent leadership (sensitivity of ethics, spirituality, positive engagement, community response) significantly to the positive performance of the organization, the effectiveness of the commitment, and organization citizenship behavior.

Climate Benevolent Leadership and Ethics

Research is seen to contribute to the leadership of benevolent and Ethics Climate is Shin et al. (2015), about the ethics of the leadership of top management and company performance through the Ethics Climate with the title of "Top Management Ethical Leadership and Firm Performance: mediating Role of Ethical and Procedural Justice Climate ". Variable ethical leadership is measured using the Likert Scale developed by Brown et al. (2005), the Ethics Climate using a scale developed by Trevino et al. (1998) and Victor and Cullen (1988), procedural Climate Justice using a scale developed Ehrhart (2004) and Walumbwa et al. (2010), firmlevel organization citizenship behavior using a scale developed Ehrhart (2004); Mayer et al. (2009); Walumbwa et al. (2010); Financial Performance using a scale developed by Chun et al. (2013). This study uses 4468 employees working in 147 companies in Korea. The analytical method used is structural equation modeling. The results showed that ethical leadership of top management has significant positive in organizational results, top management leadership ethics has positively realsionship with Ethics Climate, ethical leadership of top management in enterprise-level organization citizenship behavior and financial performance significantly mediated by Ethics Climate and climate procedural fairness. 


\section{CONCEPTUAL FRAMEWORK}

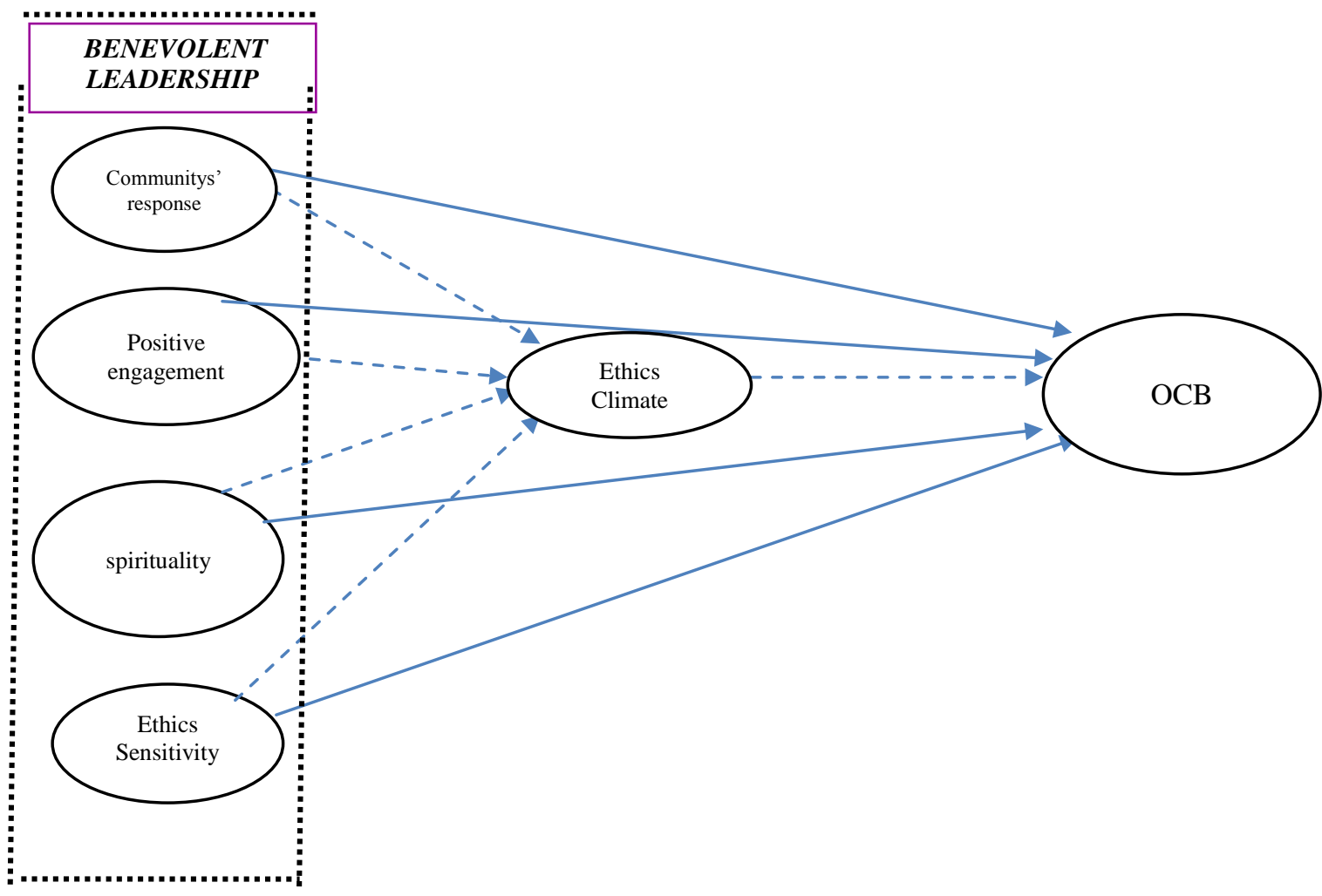

\section{Research hypothesis}

Based on evidence from previous studies between variables as well as the conceptual framework proposed, the hypothesis is formulated as follows:

H1 (a): Ethics Sensitivity has positive effect on OCB;

H1 (b): Ethics Climate mediating influence between the ethical sensitivity of the OCB;

$\mathrm{H} 2$ (a): Spirituality has positive effect on OCB;

$\mathrm{H} 2$ (b): Ethics Climate mediates the influence of spirituality on OCB;

$\mathrm{H} 3$ (a): Positive engagement has positive affects on OCB;

H3 (b): Ethics Climate mediating influence between positive engagement on OCB;

H4 (a): Communitys' response has positive effect on OCB;

H4 (b): Ethics Climate mediating influence between the community's response on OCB;

H5: Ethics Climate has positive effect on OCB;

\section{METHODOLOGY}

Population is a complete collection of all elements of similar but can be distinguished due to its characteristics (Supranto, 2010). Elements of the population are every member of the population was observed (Ferdinand, 2006). The population is all principals at various levels in Department of Education and Culture in Kendari totaling 200 employees. Collecting data in this study done by the census, not by means of sampling. Sensus is a data collection method in which all elements of the population studied one by one (Supranto, 2010). The method of data analysis used is Path Analysis. 


\section{RESULT AND DISCUSSION}

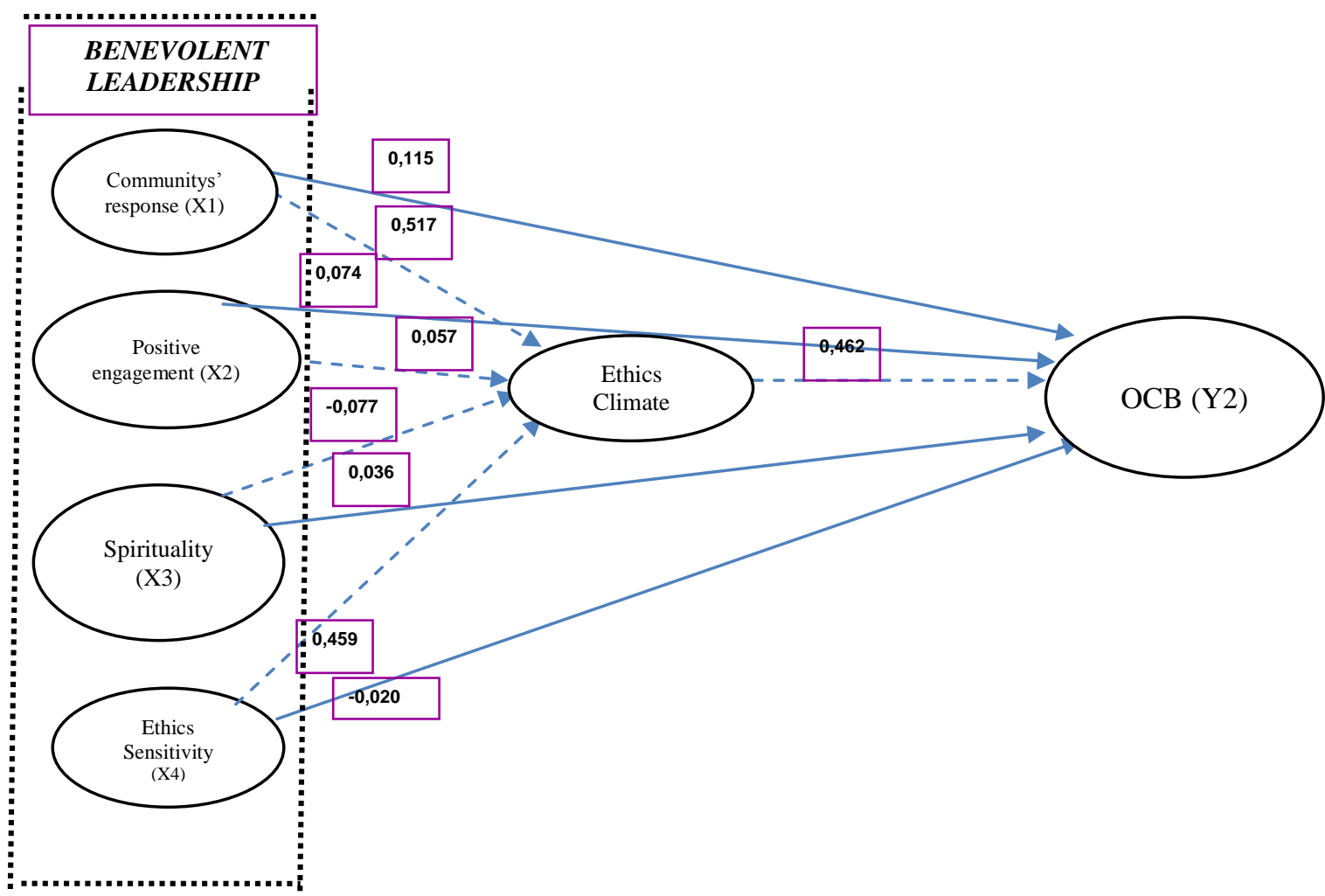

\section{Hypothesis 1 (a): The Effect of ethics sensitivity on OCB}

Testing the hypothesis with the analytical approach track to generate the path coefficient direct influence ethics sensitivity on OCB to the value of 0.115 with $p$-value $=0.000$. Because p-value $<0.05$, then the hypothesis that the ethics sensitivity has significant and positive effect on OCB acceptable. The coefficient of 0,115 lines with significant of 0.00 indicates a direct influence ethical sensitivity has significant positive towards OCB and unidirectional, meaning that the higher the ethics sensitivity, the higher ethics OCB. So it can be said that the direct effect of ethical sensitivity has significant positive and direction on OCB Department of Education and Culture in Kendari .

\section{Hypothesis 1 (b): Thw Effect of Ethics Climate mediation between ethics sensitivity on OCB}

Hypothesis testing is done through the mediation causal procedure steps and Sobel test. Procedure causal steps performed by estimating three regression equations, first, regression direct influence of independent variables / ethics sensitivity (X1a) to variable mediation / Ethics Climate (Y1), second, dependent variable (Y2) to independent variable / ethics sensitivity (X1a) third, the dependent variable / OCB (Y2) on two independent variables / ethics sensitivity (X1a) and mediation / Ethics Climate (Y1). If the independent variable / ethics sensitivity (X1a) on the dependent / OCB (Y2) was lower in the third equation compared to the second equation, then there has been a mediation (Baron and Kenny, 1986).

Sobel test is done by testing the strength of the indirect influence of independent variables / ethics sensitivity (X1a) to the dependent variable / OCB (Y2) through the mediation of Ethics Climate variables (Y1). The indirect effect (X1a) to (Y2) through (Y1) is calculated by multiplying the track (X1a) $\rightarrow$ (Y1) (a) with lines $(\mathrm{Y} 1) \rightarrow \mathrm{Y}(\mathrm{Y} 2)$ or $\mathrm{ab}$. So coefficients $\mathrm{ab}=(\mathrm{c}-\mathrm{c}$ '), where $\mathrm{c}$ is the influence (X1a) to (Y2) without control (Y1), whereas $c^{\prime}$ is the coefficient of influence (X1a) to (Y2) after control (Y1). Further test results Sobel included to the value of the coefficient ab $t$ significant test indirect effect.

The result of the calculation of causal steps third equation regression dependent variable / OCB (Y2) on two independent variables / ethics sensitivity (X1a) and mediation / Ethics Climate (Y1) of (0.053) is lower than the second equation the dependent variable / OCB (Y2) against independent variable / ethics sensitivity (X1a) of (0.115), it was concluded there has been a mediation ethics sensitivity on OCB through Ethics Climate (causal test steps attached). Sobel test values obtained $\mathrm{z}(6.289)>\mathrm{t}$ table value (1.972), meaning that there is no direct influence between ethics sensitivity (X1a) of the OCB (Y2) through Ethics Climate (Y1). Taking into account the results of the calculation of causal steps and the Sobel test, the research hypothesis which states the Ethics Climate mediates the relationship between the sensitivity of conduct with OCB acceptable. That is a 
strong Ethics Climate mediates the relationship between ethics sensitivity on OCB in Department of Education and Culture in Kendari.

\section{Hypothesis 2 (a): The influence of spirituality on OCB}

Testing the hypothesis with the approach path analysis coefficient spiritualism track direct influence on OCB with a value of 0.036 with a p-value $=0.415$ suggests the hypothesis that states spirituality has positive effect on OCB rejected. Path coefficient value of 0.036 with 0.415 significant figures show the direct influence on OCB spiritualism is not significant, which means that changes in value occurred in spiritualism that does not affect the value of OCB. So it can be said that the direct effect ethics sensitivity on OCB in Department of Education and Culture in Kendari insignificant.

\section{Hypothesis 2 (b): Effect of Ethics Climate mediation between spirituality on OCB}

Sobel test is done by testing the strength of the indirect influence of independent variables / spirituality (X2a) to the dependent variable / OCB (Y2) through the mediation of Ethics Climate variables (Y1). The indirect effect $(\mathrm{X} 1 \mathrm{a})$ to $(\mathrm{Y} 2)$ through (Y1) is calculated by multiplying the track $(\mathrm{X} 2 \mathrm{a}) \rightarrow(\mathrm{Y} 1)$ (a) with lines $(\mathrm{Y} 1) \rightarrow \mathrm{Y}(\mathrm{Y} 2)$ or $\mathrm{ab}$. So coefficients $\mathrm{ab}=(\mathrm{c}-\mathrm{c}$ '), where $\mathrm{c}$ is the influence (X2a) to (Y2) without control (Y1), whereas $c^{\prime}$ is the coefficient of influence (X2a) to (Y2) after control (Y1). Further test Sobel results included to the value of the coefficient ab t significant test indirect effect. Statistically, test Sobel have more power than the more formal methods (Preacher and Hayes, 2004).

Sobel test results obtained by the $\mathrm{z}$ score $(0.896)>\mathrm{t}$ table $(1.972)$, meaning that there is no indirect effect of spirituality on OCB through Ethics Climate. Taking into account the results of the test Sobel, the research hypothesis which states the Ethics Climate mediates the relationship between the sensitivity of conduct with OCB unacceptable. That is a strong Ethics Climate does not mediate the relationship between spirituality on OCB in Department of Education and Culture in Kendari.

\section{Hypothesis 3 (a): The Effect of positive engagement on OCB}

Testing the hypothesis with the analytical approach track to generate the path coefficient direct influence positive engagement on OCB with a value of 0.036 with a p-value $=0.464$ shows the hypothesis stating that positive engagement has affects OCB rejected. Path coefficient value of 0.036 with 0.464 significant figures show the direct influence of the OCB positive engagement is not significant, meaning that the value changes that occur in positive engagement does not affect the value of OCB. So it can be said that the direct effect positive engagement on OCB in Department of Education and Culture in Kendari has not significant.

\section{Hypothesis 3 (b): Effect of Ethics Climate mediation between positive engagement on OCB}

Sobel test is done by testing the strength of the indirect influence of independent variables positive engagement $(\mathrm{X} 3 \mathrm{~b})$ to the dependent variable / OCB (Y2) through the mediation of Ethics Climate variables (Y1). The indirect effect (X3b) to (Y2) through (Y1) is calculated by multiplying the track (X3b) $\rightarrow$ (Y1) (a) with lines $(\mathrm{Y} 1) \rightarrow \mathrm{Y}(\mathrm{Y} 2)$ or $a b$. So coefficients $a b=(\mathrm{c}-\mathrm{c}$ '), where $\mathrm{c}$ is the influence (X3b) to (Y2) without control (Y1), whereas $c^{\prime}$ is the coefficient of influence (X2a) to (Y2) after control (Y1). Furthermore Sobel test results included in the calculations to obtain the value of the coefficient ab $t$ significant test indirect effect. Statistically, test Sobel have more power than the more formal methods

Sobel test results obtained by the $\mathrm{z}$ score $(-1.385)>\mathrm{t}$ table $(-1.972)$, meaning that there is no direct effect between positive engagement on OCB through Ethics Climate (Y1). Taking into account the results of the Sobel test, the research hypothesis which states the Ethics Climate mediates the relationship between positive engagement with the OCB is not accepted. That is a strong Ethics Climate does not mediate the relationship between positive engagement on OCB in Department of Education and Culture in Kendari.

\section{Hypothesis 4 (a): The Effect of community response to OCB}

Testing the hypothesis with the analytical approach track to generate the path coefficient direct influence community response to OCB the value of -0.020 with $p$-value $=0.722$ shows the hypothesis community Response has positive effect on OCB rejected. The coefficient of -0.020 paths with significant of $=0.722$ figure shows the direct influence of the community response to OCB is not significant, meaning that the value changes that occur in community response does not affect the value of OCB. So it can be said that the direct effect on the community response to OCB not significant.

\section{Hypothesis 4 (b): Effect of Ethics Climate mediation between community response on OCB}

Sobel test is done by testing the strength of the indirect influence of independent variable / community response (X4b) to the dependent variable / OCB (Y2) through the mediation of Ethics Climate variables (Y1). 
The Effect Of Benevolent Leadership On Organizational Citizenship Behavior (OCB) : Mediating ..

The indirect effect $(\mathrm{X} 4 \mathrm{~b})$ to $(\mathrm{Y} 2)$ through $(\mathrm{Y} 1)$ is calculated by multiplying the track $(\mathrm{X} 3 \mathrm{~b}) \rightarrow(\mathrm{Y} 1)$ (a) with lines $(\mathrm{Y} 1) \rightarrow \mathrm{Y}$ (Y2) or $\mathrm{ab}$. So coefficients $\mathrm{ab}=\left(\mathrm{c}-\mathrm{c}^{\prime}\right)$, where $\mathrm{c}$ is the influence (X4b) to (Y2) without control (Y1), whereas $c^{\prime}$ is the coefficient of influence (X4b) to (Y2) after control (Y1). Furthermore Sobel test results included in the calculations to obtain the value of the coefficient ab $t$ significant test indirect effect.

Sobel test results obtained by the $\mathrm{z}$ score $(5,580)>$ nilai $t$ table $(1.972)$, meaning that there is an indirect effect of the community response to OCB through Ethics Climate. Taking into account the results of the test Sobel, the research hypothesis which states Ethics Climate mediates the relationship between the community response to OCB acceptable. That is a strong Ethics Climate mediates the relationship between a community's response to the OCB in Department of Education and Culture in Kendari.

\section{Hypothesis 5: The Effect of Ethics Climate on OCB}

Testing the hypothesis with the analytical approach track to generate the path coefficient direct influence Ethics Climate on OCB with a value of 0.426 with a p-value $=0.000$. Because $p$-value $<0.05$, then the hypothesis that Ethics Climate has significant positive effect on OCB acceptable. The coefficient of 0,462 lines with significant numbers of 0.00 indicates a direct influence on OCB positive Ethics Climate significantly and unidirectional, meaning that the higher of Ethics Climate the higher of OCB. So it can be said that the direct effect of Ethics Climate has positive and significant on OCB in Department of Education and Culture in Kendari.

\section{CONSLUSSION}

Ethics sensitivity has significant and positive effect on OCB. Ethics Climate mediates the relationship between ethics sensitivity and OCB. Spirituality has no effect on OCB. Ethics Climate does not mediate the relationship between spirituality and OCB. Positive engagement does not affect the OCB. Ethics Climate does not mediate the relationship between Positive engagement and OCB. Community response had no effect on OCB. But Ethics Climate mediates the relationship between community response and OCB. Ethics Climate has significant and positive effect on OCB.

\section{REFERENCES}

[1]. Armstrong, Michael. 2010. “Essential Human Resource Management Practice”: A Guide To People Management. London: Kogan Page Limited.

[2]. Bass, Bernard M. and Riggio, Ronald E. 2006. Transformational leadership. New Jersey: Lawrence Erlbaum Associates, Inc.

[3]. Bowditch, J. L. Buono, A. F. 1990. “A primer on organizational behavior”. New York: John Wiley \& Sons.

[4]. Daft, Richard L. 2010. Organization Theory and Design, Tenth Edition. South-Western: Cengage Learning

[5]. Echols John M. Shadily, Hassan. 2010. "Kamus Inggris Indonesia; An English-Indonesian Dictionary”. Jakarta: PT Gramedia.

[6]. Fry, Louis W. 2003. "Toward A Theory of Spiritual Leadership". Tarleton State University-Central Texas, 2003 South Clear Creek Road, Killeen, Tx 76549, USA.

[7]. Fry, Louis W. Cohen, Melanie P. 2009. "Spiritual Leadership As A Paradigm For Organizational Transformation and Recovery From Extended Work Hours Cultures”. Journal Of Business Ethics 84:265-27. Doi 10.1007/S10551-008-9695-28.

[8]. Gosh, Koustab. 2015. "Benevolent leadership in not-for-profit organizations: welfare orientation measures, Ethics Climate and organizational citizenship behavior”. Leadership \& Organization Development Journal. Vol. 36 Iss 5 pp. http://dx.doi.org/10.1108/LODJ-12-2013-0164

[9]. Harsono. 2010. Perencanaan Kepegawaian. Bandung: Fokus Media

[10]. Karakas, Fahri. Sarigollu, Emine. 2012. "Benevolent Leadership: Conceptualization and Construct Development", Journal of Business Ethics, Vol. 108 No. 7, pp. 537-53. DOI 10.1007/s10551-011-1109-1

[11]. Karakas, Fahri. Sarigollu, Emine. Manisaligil, Alperen. 2013. "The Use Of Benevolent Leadership Development To Advance Principles of Responsible Management Education"; Journal Of Management Development Vol. 32 No. 8, Pp. 801-822. Http://Dx.Doi.Org/10.1108/Jmd-08-2011-0102.R1

[12]. Karakas, Fahri. 2010. "Spirituality and Performance In Organizations". A Literature Review". Journal of Business Ethics 94:89106. Doi 10.1007/S10551-009-0251-5.

[13]. Katz, Daniel. 1964. "Motivational Basis of Organizational Behavior”. Behavioral Science, 9,131-146

[14]. Luthans, Fred. 2011. Organizational Behavior. New York: McGraw-Hill Companies, Inc.

[15]. Nawawi, Hadari. 2006. Evaluasi Dan Manajemen Kinerja di Lingkungan Perusahaan dan Industri. Yogyakarta: Gadjah Mada University Press.

[16]. Organ, D. W. 1988. “Organizational Citizenship Behavior: The Good Soldier Syndrome, Lexington, Ma: Lexington Books

[17]. Organ, D. W. 1990. “The Motivational Basis of Organizational Citizenship Behavior: Lexington Books.

[18]. Organ, D.W. Ryan K. 1995. “A Meta-Analytic Review of Attitudinal and Dispositional Predictors of Organizational Citizenship Behavior”. Personnel Psychology, 48, 775-800

[19]. Organ, W. Podsakoff P.M. MacKenzie. 2006. Organizational Citizenship Behavior; Its Nature Antecedents and Consequences. California: Sage Publications, Inc.

[20]. Pearce J1, Greggerdsen. 1991. "Task Interdepedence and Extra Role Behavior: A Test of The Mediating Effects of Felt Responsibility": Journal of Applied Psychology, Vol. 6, pp. 838-844.

[21]. Podsakoff, P. M., MacKenzie, S. B., Paine, J. B. and Bachrach, D. G. (2000), "Organizational Citizenship Behavior: A Critical Review of The Theoretical and Empirical Literature and Suggestions For Future Research", Journal of Management, Vol. 26 No. 3 , pp. 513-63.

[22]. Rianse, Usman. 2012. “Anak Pinggiran Menggapai Impian”. Kendari: Unhalu Press.

[23]. Robbins and Coulter. 2012. "Management 11 Ed". New Jersey: Pearson Education, Inc.

[24]. Robbins and Judge, (Alih bahasa Ratna Saraswati dan Febriella Sirait). 2013. "Organizational Behavior 16 ${ }^{\text {th }}$ Ed". (Perilaku Organisasi Edisi Keenam Belas) Jakarta: Salemba Empat. 
[25]. Robbins and Judge. 2013. "Organizational Behavior 15 th Ed". USA: Pearson Education, Inc

[26]. Schein, Edgar H. 2004. "Organizational Culture and Leadership”. San Francisco: Jossey-Bass

[27]. Walumbwa, Fred O. Mayer, David M. Wang, Peng. Wang, Hui. Workman, Kristina. Christensen, Amanda L. 2011. “Linking Ethical Leadership To Employee Performance: The Roles of Leader-Member Exchange, Self-Efficacy, and Organizational Identification". Organizational Behavior and Human Decision Processes 115 204-213

[28]. Zehir, Cemal. Müceldili, Büsra. Altindag, Erkut. Sehitoglu, Yasin. Zehir, Songül. 2014. "Charismatic Leadership and Organizational Citizenship Behavior: The Mediating Role of Ethics Climate”. Social Behavior and Personality, 2014, 42(8), 13651376 